\title{
A cross-sectional study of the prevalence and factors associated with symptoms of perinatal depression and anxiety in Rwanda
}

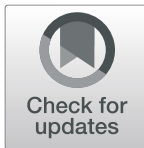

Marie Providence Umuziga ${ }^{1 *}$ (D, Oluyinka Adejumo ${ }^{1}$ and Michaela Hynie ${ }^{2}$

\begin{abstract}
Background: Perinatal depression and anxiety are increasingly recognized as important public health issues in low and middle-income countries such as Rwanda and may have negative consequences for both mothers and their infants. Maternal mental health may be particularly challenged in Rwanda because of the prevalence of risk factors such as poverty, low education levels, negative life events and marital problems. However, there are limited data about perinatal depression and anxiety symptoms in Rwanda. This study thus aimed to explore the prevalence of symptoms of perinatal depression and anxiety in Rwanda, and factors associated with them.
\end{abstract}

Methods: A sample of 165 women in the perinatal period (second and third trimester of pregnancy, up to 1 year postnatal) were interviewed individually over 1 month in October 2013. Women were interviewed at 5 of 14 health centres in the Eastern Province or the affiliated district hospital. Participants answered socio-demographic questions and scales measuring symptoms of perinatal depression (EPDS: Edinburgh Postnatal Depression Scale) and anxiety (SAS: Zung Self-rating Anxiety Scale).

Results: Among women in the antenatal period $(N=85), 37.6 \%$ had symptoms indicating possible depression (EPDS $\geq 10$ ) and $28.2 \%$ had symptoms associated with clinical levels of anxiety (SAS > 45). Among women within the postnatal period $(N=77), 63.6 \%$ had symptoms of possible depression, whereas $48,1 \%$ had symptoms of probable anxiety. Logistic regression showed that symptoms of postnatal depression were higher for respondents who had four or more living children relative to those having their first child (Odds Ratio: 0.07, C.I. = 0.01-0.42), and for those with a poor relationship with their partner (Odds Ratio: .09, C.I. $=0.03-0.25$ ). Any lifetime exposure to stressful events was the only predictor of symptoms of postnatal anxiety (Odds Ratio $=0.20$, C.I. $=0.09-0.44$ ).

Conclusions: Symptoms of postnatal depression and anxiety were prevalent in this Rwandan sample and most strongly predicted by interpersonal and social factors, suggesting that social interventions may be a successful strategy to protect against maternal mental health problems in the Rwandan context.

Keywords: Perinatal depression, Perinatal anxiety, Maternal mental health, Social support, Rwanda, Social factors of mental health

\footnotetext{
* Correspondence: umuprov20@yahoo.com

${ }^{1}$ School of Nursing, College of Medicine and Health Sciences, University of

Rwanda, 3286, Kigali, Rwanda

Full list of author information is available at the end of the article
}

(c) The Author(s). 2020 Open Access This article is distributed under the terms of the Creative Commons Attribution 4.0 International License (http://creativecommons.org/licenses/by/4.0/), which permits unrestricted use, distribution, and reproduction in any medium, provided you give appropriate credit to the original author(s) and the source, provide a link to the Creative Commons license, and indicate if changes were made. The Creative Commons Public Domain Dedication waiver (http://creativecommons.org/publicdomain/zero/1.0/) applies to the data made available in this article, unless otherwise stated. 


\section{Background}

Depression and anxiety occurring in the perinatal period, the time during pregnancy and up to 1 year following birth, can have serious consequences for women's mental health and for that of their infants [1-6]. Perinatal depression and anxiety are associated with reduced social participation among mothers and maternal sensitivity to their infants with elevated risks of infant malnutrition, increased rates of physical illness and subsequent depressive episodes [7-13].

Perinatal depression and anxiety are referred to as Common Perinatal Mental Disorders (CPMDs) as they represent the most common mental health problems faced by women during the perinatal period $[14,15]$. Rates of first onset and severe depression are three times higher in the postnatal period than in other periods of women's lives, suggesting that this is a particularly vulnerable time [16]. There is also increasing evidence that CPMDs are two to three times more prevalent among pregnant women and mothers of infants in low-income countries (LMICs), including Rwanda, than in high-income countries [17-19].

A systematic review of studies conducted in LMICs reported that the prevalence of CPMDs was 15.6 and 19.8\% antenatally and postnatally, respectively [20]. In a recent study by Gelaye and colleagues [21], the prevalence rates of antenatal depression in LMICs ranged between 19 to 25\% whereas postnatal depression prevalence was between 10 to $20 \%$. For anxiety, the global estimates are about $14-16 \%$ during pregnancy and $8-10 \%$ postnatally [19]. On the African continent, prevalence rates vary widely. It has been shown that the estimated prevalence of CPMDs in subSaharan Africa ranges from 12.5 to $27.1 \%$ in pregnancy and from 10.0 to $34.5 \%$ postnatally $[1,22]$. A systematic review by Sawyer and colleagues found that rates of depression were 11.3 and $18.3 \%$ during ante- and postnatal periods, respectively [18], whereas prevalence rates of antenatal and postnatal anxiety were 14.8 and $14 \%$ respectively [18]. Other studies, however, have found even higher rates. In a low-income setting in Cape Town, 39\% of pregnant women screened positive on the Edinburgh Postnatal Depression Scale (EPDS: scores $\geq 14$ ) for depressed mood and $34.7 \%$ of postnatal women were diagnosed with depression [23]. In a study conducted in Uganda, $43 \%$ of the participants were found to have postpartum depressive symptoms on the EPDS (scores 210 ) [24]. Rates may vary according to whether the tools in these cited studies were screening tools or diagnostic tools or interviews, as well as the use of different cut offs, with the EPDS.

Elevated rates have also been found for anxiety, which has been less widely studied in Africa. In a review of studies from Africa, the antenatal and postnatal anxiety prevalence rates were 14.8 and $14 \%$, respectively [18]. However, the relative prevalence across the perinatal period varies widely by study. With some recent studies reporting a higher prevalence of anxiety in the antenatal period $[25,26]$ than in the postnatal period $[26,27]$. The elevated rates of CPMDs in low-income countries may be attributed to difficult living conditions experienced in these settings. This includes both material and social challenges and exposure to stressful life events. Known risk factors for maternal mental health problems include social factors such as poverty, low education levels; poor social support and relationship factors like marital problems $[13,24]$. In addition to stressful life events, cultural traditions and values may also alleviate or exacerbate the development of CPMDs [15, 28]. In some regions, being a single mother or having a baby out of marriage is not socially acceptable and stigma or rejection associated with single motherhood can contribute to the development of symptoms of CPMDs [28, 29]. On the other hand, research suggests that in some cultural settings women may receive extra attention after birth, particularly in the first month. In these situations, a woman is typically attended by female relatives or in-laws. Expecting this support but not receiving it may contribute to the development of CPMDs [15, 28, 29].

Many of the known risk factors are widely prevalent in Rwanda; a small East African country of almost 12 million people that is in the bottom third of the Human Development Index [30]. To our knowledge, there is no published research about CPMDs in Rwanda, but available literature indicates that mental health problems such as anxiety and depression are prevalent in the Rwandan population [31, 32]. However, rates of antenatal and postnatal anxiety and depression may be particularly high in the Rwandan context. This study was therefore aimed at determining the prevalence and associated factors of CPMDs (anxiety and depression) in a selected district hospital of the Eastern Province in Rwanda.

\section{Methods \\ Study design and setting}

A descriptive quantitative cross-sectional survey was used to measure the prevalence, and factors associated with, the symptoms of CPMDs in a sample of women receiving regular antenatal care and infant immunization. The study was conducted at 5 of 14 health centres (HCs), which were selected using simple random sampling by picking the number assigned to each health centre from a box, and at their affiliated district hospital in the Eastern Province in Rwanda. The administrative district of the study setting is a primarily rural district with one main town serving as the district capital and has 14 health centres, which function as primary health facilities [33]. This province is one of the most populated but has poorer health indicators as compared to other districts in Rwanda. The Rwandan Ministry of Health's data suggest that $66.1 \%$ of women in the selected district deliver in health facilities (national 
average $=69.2 \%$, the district is ranked 16th of 30 districts), $97.4 \%$ attend at least one antenatal care visit (national average $=98.0 \%$, rank 20 of 30 districts), and $21 \%$ attend at least four visits (national average $=35.4 \%$, rank 29 of 30 districts) [34].

\section{Participants}

The study population comprised pregnant women attending antenatal care (ANC) or infant immunization in $5 \mathrm{HCs}$ or the affiliated district hospital. To obtain the required sample, a systematic sampling technique was used to recruit a sample of 165 women into the study. Only women over 15 years of age who were pregnant or had a child up to 1 year of age were included. Women during childbirth or in the first 2 weeks postpartum were excluded because of unstable mood associated with physiological changes in the early weeks postpartum [8].

\section{Materials}

The questionnaire had two parts; the first part asked about the socio-demographic characteristics of participants and factors associated with perinatal depression and anxiety identified in past research. Sociodemographic questions included in this analysis are age (classified as less than 24,25 to 29,30 to 34 , and 35 and older); marital status (single, married, living together, separated/divorced); education (no formal education, any amount of primary school, any secondary school or tertiary); own and husband's occupation (employed by other, unemployed, self-employed, no permanent job); number of children born to the mother who are still living $(0,1,2,3,4$ or more); pregnancy status (pregnant or not); and whether the child or pregnancy was planned (yes/no). Participants were asked about lifetime exposure to stressful events, such as any form of abuse in childhood, sexual abuse, poverty, loss of their husband or child, intimate partner violence, family mental illness or personal illness. Because of a coding error, it was not possible to determine who experienced more than one of these lifetime stressors so stressful events were coded as none versus at least one. Social factors included loss of nuclear family members (parents and siblings alive, lost a parent, lost a sibling, lost both parents and siblings) and the nature of the relationship with the husband (strong/poor). The full survey in English and Kinyarwanda is available as a Additional file 1.

The second part included screening tools widely used and validated across a range of cultural settings from LMICs including Africa $[1,8,24,27,35,36]$. The Edinburgh Postnatal Depression Scale (EPDS) is composed of 10 questions using a 0 to 3 Likert scale [24, 37]. The maximum score is 30 . Research conducted in a low resource setting in Uganda, a setting similar to Rwanda, found possible (as opposed to probable) depression at scores of 10 or greater [24], which is consistent with research in other LMICs [20, 24, 37, 38].. Thus, a score of 10 or greater was considered for possible depression in this study. The Zung Self-rating Anxiety Scale (SAS) consists of 20 items rated on a 1-4 Likert scale [27, 39]. The total SAS raw score ranges from 20 to 80; previous studies in LMICs have used a score below 45 to indicate a normal range of anxiety; $45-59$ moderate; $60-74$ severe and 75 and over indicates extreme anxiety [27, 39]. These standardized scales used were found to be reliable; the Cronbach's alpha was 0.89 and 0.87 for EPDS and SAS respectively.

The full questionnaire was translated into Kinyarwanda by a professional translator and a mental health expert to confirm the validity of the translation. It was backtranslated to English by three mental health experts, who also confirmed the validity of the translation. The questionnaire was also presented to Rwandan academics and mental health professionals and in other academic forums for feedback concerning the content validity and to determine the clarity and fit with research objectives. A pilot study ( $N=16$, or $10 \%$ the size of the main study) tested the feasibility of the study, the instruments and suitability of the research design. A total of 16 participants were examined under the same circumstances as the main study, however, findings were excluded from the main study. Minor adjustments for clarity of wording were made before the main study began.

\section{Procedures}

Ethical clearance letters were obtained and permission from the district hospital management was granted. Data collection was then conducted by a research assistant who was an experienced mental health nurse. The research assistant was introduced to each mother by the nurse or midwife in charge of the services while participants were waiting for their follow-up care or that of their infants. He explained the research to them individually and invited them to participate. All participants received a complete description of the study and signed a written consent form prior to participation.

Regular antenatal visits are held on 1 day each week at each health centre. Likewise, immunization is held on 1 day per week at each health centre. Each health centre was visited twice, once on their antenatal visit day and once in the same week on their immunization day. A systematic sampling technique was used, with every 5 th eligible client who presented on that day being admitted into the study [40]. Approximately 15 additional participants were recruited from the paediatric ward of the district hospital by asking women waiting in the ward the age of their children, and again selecting every 5th eligible client to participate. 


\section{Ethical considerations}

Ethical approval from the Senate Research Committee of the University of Western Cape/ South Africa (Certificate: 13/8/9) and Kigali Health Institute/ Rwanda Institutional Review Board (Certificate: KHI/IRB/26/2013) was obtained, as well as written permission to collect data from the Director of the hospital. All participants provided written consent. Participants under the age of 18 (the age of majority in Rwanda) signed assent forms and their parents/guardians provided written consent. Participants who were found to have EPDS scores above 10 (possible depression) or who endorsed item 10 (suicidal thoughts), and also participants who had SAS scores above 60 (severe anxiety), were first informed of their scores and then allowed to decide whether or not to seek treatment. If they accepted treatment they were helped to make an appointment with the mental health team after they had completed their medical appointment.

\section{Data analyses}

The Cochran formula for small populations was used to determine the sample required for analysis [41], thus the total number of 165 of the sample population was obtained.

Analyses were conducted using SPSS v. 21 and proceeded through the following steps: 1) Cronbach's alphas were used to test for reliability on the EPDS and SAS; 2) Categorical variables were created. Age was recategorized into 5-year increments, however, the number of women aged 15 to 19 was too small for meaningful analysis $(n=4)$ and so the youngest two categories were combined into one category of 24 and younger for multivariate analyses. Education originally had categories for both secondary and tertiary education but with only 4 participants reporting any tertiary education, this was combined with the secondary category. EPDS was recategorized into 2 levels based on standard cut off scores for possible depression (10 or greater). SAS was recategorized according to standard cut off scores for probable anxiety ( $\geq 45) ; 3)$. Frequencies were used to describe the categorical risk variables, and means and standard deviations were also calculated for the two clinical dependent variables. 4) Bivariate chi-square tests of independence were used to determine the relationship between all predictor variables with the two categorical psychological symptom variables (i.e., EPDS and SAS). A significant strong relationship was observed for the two dependent variables of depression and anxiety symptomatology (Cramer's $\mathrm{V}=.55$ ), suggesting that they may be measuring the same underlying construct but since they were analysed separately this was not an issue for analysis; 5) Separate logistic regression models regressed each individual psychological symptom variable (EPDS and SAS) onto only those risk variables that were significantly associated with them at $p<0.05$ in the bivariate tests. All predictor variables were entered in the same step. Model fit was assessed using the Hosmer-Lemeshow Goodness of Fit test with a critical value of $p=0.05$. Odds Ratios are reported for each variable, along with their respective confidence intervals. Interaction terms were not included to test moderation because of the number of variables and the sample size; dividing the sample into those women in the antenatal versus postnatal period resulted in limited power and so multivariate analyses were conducted on the entire sample.

\section{Results}

Univariate analyses were used to summarize data in terms of frequency distributions of the variables under study. In this case, socio-demographic variables,information about husband/ partner (relationship with husband/ partner and occupation) as well as other variables such as loss of nuclear family members, number of children, planned pregnancy, and stressful events are described in terms of frequency and distribution. In addition, the distribution of respondents by EPDS and SAS scores and perinatal period is also included.

\section{Sample and socio-demographic characteristics of participants}

The sample comprised of 165 participants from age 15 years and above. Participants' characteristics are provided in Table 1. About half (51.5\%) of the sample were pregnant. The most frequent age category was those aged $25-29$ years (38.2\%) (see Table 1). Almost half of the respondents were married (44.8\%). Most were unemployed (77\%) and had a primary school level of education only (60.6\%). A total of 96 participants $(58.2 \%)$ had experienced at least one highly stressful life event. As shown in Table 1, 35.7\% of respondents had both parents and siblings alive, but the majority of respondents had lost at least one immediate family member, although the reason for this loss (i.e. illness, accident or violence) was unknown. More than a third (40.6\%) reported an unplanned pregnancy. Of those living with husband/partners (86.7\%), most participants (46\%) reported that their husbands/partners were unemployed. When rating the overall quality of the relationship (strong versus poor), more than a half of participants $(69.1 \%)$ reported a strong relationship with husband/partner while $30.9 \%$ reported a poor relationship.

Prevalence of perinatal depression and anxiety symptoms Scores on the Edinburgh Post-natal Depression Survey (EPDS) for the entire sample ranged from 0 to $30(M=$ $10.8, S D=8.13)$. Women who reported 10 or greater scores on the EPDS were coded as having symptoms of depression. Self-Rating Anxiety (SAS) scores ranged from 23 to $74(M=42.2, S D=12.31)$. SAS was coded as "0" for the respondents with normal range anxiety and 
Table 1 Socio-demographic characteristics among women in selected health centres and the affiliated district hospital in Rwanda

\begin{tabular}{|c|c|c|}
\hline Demographic characteristics & Frequency $(n=165)$ & Percent (\%) \\
\hline \multicolumn{3}{|l|}{ Age in years } \\
\hline $15-19$ & 9 & 5.5 \\
\hline $20-24$ & 46 & 27.9 \\
\hline $25-29$ & 63 & 38.2 \\
\hline $30-34$ & 26 & 15.8 \\
\hline 35 or over & 21 & 12.7 \\
\hline \multicolumn{3}{|l|}{ Marital status } \\
\hline Single & 8 & 4.8 \\
\hline Married & 74 & 44.8 \\
\hline Living together & 69 & 41.8 \\
\hline Separated/divorce & 14 & 8.5 \\
\hline \multicolumn{3}{|l|}{ Level of education } \\
\hline No education & 43 & 26.1 \\
\hline Primary & 100 & 60.6 \\
\hline Secondary & 18 & 10.9 \\
\hline Tertiary & 4 & 2.4 \\
\hline \multicolumn{3}{|l|}{ Participants'occupation } \\
\hline Employed by other & 3 & 1.8 \\
\hline Unemployed & 127 & 77.0 \\
\hline Self-employed & 31 & 18.8 \\
\hline No permanent job & 4 & 2.4 \\
\hline \multicolumn{3}{|l|}{ Participants' nuclear family } \\
\hline Both parents/siblings alive & 59 & 35.7 \\
\hline Lost a parent & 49 & 29.7 \\
\hline Lost a sibling & 30 & 18.2 \\
\hline Lost both parents/all siblings & 27 & 16.4 \\
\hline \multicolumn{3}{|l|}{ Number of children } \\
\hline No child & 29 & 17.6 \\
\hline One & 43 & 26.1 \\
\hline Two & 39 & 23.6 \\
\hline Three & 20 & 12.1 \\
\hline Four or more & 34 & 20.6 \\
\hline \multicolumn{3}{|l|}{ Planned pregnancy } \\
\hline Yes & 98 & 59.4 \\
\hline No & 67 & 40,6 \\
\hline Total & 165 & 100 \\
\hline
\end{tabular}

"1" for those with scores for probable symptoms of anxiety (moderate and severe; SAS $>45$ ). The findings indicate that half $(50.3 \%)$ had symptoms of depression on the EPDS whereas $37 \%$ had scores above the cut-point rates (probable symptoms of anxiety) for SAS.

The proportion of women in the postnatal period with symptoms of depression $(N=49,63.6 \%)$ and anxiety
$(N=37,48.1 \%)$ was higher than the proportion with symptoms of depression $(N=32: 37.6 \%)$ and anxiety $(N=24,28.2 \%)$ in the antenatal period; $\chi^{2}(1)=10.92$, $p<0.00$, for depressive symptoms, $\chi^{2}(1)=13.13, p<$ 0.00 , for anxiety symptoms. For the sample overall, there was a significant relationship between having elevated symptoms of depression and anxiety, with $52(31.5 \%)$ women above the cut-off point on both scales, $\chi^{2}(2)=$ 49.67, $p<0.00$, while $31(18.8 \%)$ reported only elevated symptoms of depressive symptoms and 9 (5.5\%) reported only elevated symptoms of anxiety.

\section{Factors associated with perinatal depression and anxiety symptoms}

A binary logistic regression was performed to assess the impact of factors on the likelihood of elevated symptoms of perinatal depression (EPDS >10). The model contained those independent variables that were found to have significant bivariate relationships with the EPDS: age, the highest level of education experienced, relationship with husband; the number of previous children; and having had stressful life events. The full model containing these predictors was statistically significant, $X^{2}(8)=$ 9.44, $p=0.31$. Participants who reported a good spousal relationship (Odds Ratio: 0.09, C.I. $=0.03-0.25$ ) were less likely to have elevated depressive symptoms. Those having their first child were less likely to have depressive symptoms relative to those with 4 or more (Odds Ratio: 0.07, C.I. $=0.01-0.42$ ) (see Table 2).

A logistic regression model was used to determine the extent to which the following variables were associated with elevated levels of symptoms of perinatal anxiety on the SAS: the relationship with husband, planned pregnancy, and the experience of stressful life events. The full model containing the above factors was statistically significant, $\chi^{2}(8)=5.73, p=0.68$.

The results indicate that, in a multivariate analysis, past exposure to stressful life events was the only significant correlate of symptoms of perinatal anxiety. Respondents who reported not having had any extremely stressful life events were less likely to have anxiety symptoms (Odds Ratio $=0.20$, C.I. $=0.09-0.44$ ) than those who had not (see Table 3).

\section{Discussion}

The findings of this study suggest that symptoms of depression and anxiety were relatively high among women using health clinics for basic antenatal care and infant immunization. Although we found relatively high rates of perinatal depression symptoms, they are comparable to other studies using the same cut-off of 10 for possible depression on the EPDS. A study conducted in a rural district of the neighbouring country, Uganda, also reported that elevated symptoms of postnatal depression 
Table 2 Logistic regression predicting the likelihood of symptoms of perinatal depression among women in selected health centres and the affiliated district hospital in Rwanda

\begin{tabular}{|c|c|c|c|c|c|c|c|c|}
\hline \multirow[t]{2}{*}{ Independent variables } & \multirow[t]{2}{*}{ B } & \multirow[t]{2}{*}{ Wald } & \multirow[t]{2}{*}{ df } & \multirow[t]{2}{*}{$p$} & \multirow{2}{*}{$\begin{array}{l}\text { Odds } \\
\text { Ratio }\end{array}$} & \multicolumn{2}{|c|}{ 95\% C.I. } & \multirow{2}{*}{$\begin{array}{l}\% \\
\text { Screen } \\
\text { High } \\
\text { EPDS } \\
\text { Within } \\
\text { Group }\end{array}$} \\
\hline & & & & & & Lower & $\overline{\text { Upper }}$ & \\
\hline Age & & 7.84 & 3 & 0.05 & & & & \\
\hline 24 or less & 1.06 & 1.52 & 1 & 0.22 & 2.89 & 0.53 & 15.64 & 50.9 \\
\hline $25-29$ & -0.04 & 0.00 & 1 & 0.96 & 0.96 & 0.19 & 4.74 & 46.0 \\
\hline $30-34$ & -1.03 & 1.60 & 1 & 0.21 & 0.36 & 0.07 & 1.76 & 46.2 \\
\hline 35 or more $(r)$ & & & & & 1.00 & & & 66.7 \\
\hline Level of education & & 8.74 & 2 & 0.01 & & & & \\
\hline No Education & 0.69 & 0.99 & 1 & 0.32 & 2.00 & 0.51 & 7.83 & 76.7 \\
\hline Primary & -0.78 & 1.69 & 1 & 0.19 & 0.46 & 0.14 & 1.49 & 42.0 \\
\hline Secondary or more $(r)$ & & & & & 1.00 & & & 36.4 \\
\hline \multicolumn{9}{|l|}{ Relationship with husband* } \\
\hline Strong & -2.43 & 21.16 & 1 & 0.00 & 0.09 & 0.03 & 0.25 & 34.2 \\
\hline Poor(r) & & & & & 1.00 & & & 86.3 \\
\hline Number of children* & & 10.48 & 4 & 0.03 & & & & \\
\hline No Child & -2.10 & 8.29 & 1 & 0.00 & 0.07 & 0.01 & 0.42 & 20.7 \\
\hline One & -1.32 & 2.73 & 1 & 0.10 & 0.27 & 0.06 & 1.28 & 51.2 \\
\hline Two & -0.92 & 1.37 & 1 & 0.24 & 0.40 & 0.09 & 1.86 & 46.2 \\
\hline Three & -0.13 & 0.03 & 1 & 0.87 & 0.88 & 0.18 & 4.26 & 60.0 \\
\hline Four and more (r) & & & & & 1.00 & & & 73.5 \\
\hline \multicolumn{9}{|l|}{ Stressful life events } \\
\hline None & -0.46 & 1.18 & 1 & 0.28 & 0.63 & 0.28 & 1.44 & 34.8 \\
\hline At least one (r) & & & & & 1.00 & & & 61.5 \\
\hline Constant & 3.15 & 11.12 & 1 & 0.00 & 23.36 & & & \\
\hline
\end{tabular}

*: Predictors with a $p<.05$, " $r$ ": Reference category, $d f$ degree of freedom, $p p$-value, $B$ Regression coefficients

(43\%) [24] and high rates have also been observed in some studies in South Africa (e.g., 34.7\%) [23].

Symptoms of perinatal depression were higher postnatally than antenatally. Some African studies have found higher rates of symptoms of antenatal depression than postnatal $[42,43]$. However, a recent review of research in low and middle-income countries found antenatal rates to be lower than postnatal rates [17], a pattern also obtained in high-income countries [44]. The lower prevalence of symptoms of antenatal depression should not be neglected, however, as antenatal depression is known to negatively impact on the uptake of antenatal care, foetal and obstetric outcomes, and is a strong predictor of postnatal depression [43].

The elevated rates of anxiety symptoms are also of concern. There is a growing body of research that suggests that perinatal anxiety is at least as disruptive as depression and possibly more prevalent [45], with potential adverse consequences for the mother's health, the early infant relationship and the child's health and development [18].

\section{The factors associated with symptoms of perinatal} depression and anxiety

The pervasive impact of both the immediate and larger social context on rates of symptoms of perinatal depression is apparent in the variables associated with women's perinatal mental health. Marital status was not significantly associated with symptoms of perinatal anxiety in the bivariate analysis but was associated with symptoms of perinatal depression. The latter finding is consistent with recent studies in Africa [18, 43]. For those who had a partner (common-law or married), the relationship quality was found to be a strong correlate of symptoms of both perinatal depression and anxiety. Marital problems and lack of emotional and practical support from spouses have been found to be important in the development of CPMD in several other studies in Africa [18, 23, 24].

The absence of supportive relationships, in general, is particularly salient in Rwanda, a country that has seen a profound disruption of community and family relationships as a result of the 1994 genocide against Tutsi [46]. 
Table 3 Logistic regression predicting the likelihood of symptoms of perinatal anxiety among women in selected health centres and the affiliated district hospital in Rwanda

\begin{tabular}{|c|c|c|c|c|c|c|c|c|}
\hline \multirow{2}{*}{$\begin{array}{l}\text { Independent } \\
\text { variables }\end{array}$} & \multirow[t]{2}{*}{$B$} & \multirow[t]{2}{*}{ Wald } & \multirow[t]{2}{*}{$d f$} & \multirow[t]{2}{*}{$p$} & \multirow{2}{*}{$\begin{array}{l}\text { Odds } \\
\text { Ratio }\end{array}$} & \multicolumn{2}{|c|}{ 95\% C.I. } & \multirow{2}{*}{$\begin{array}{l}\% \\
\text { Screen } \\
\text { High } \\
\text { on SAS }\end{array}$} \\
\hline & & & & & & Lower & Upper & \\
\hline \multicolumn{9}{|c|}{ Relationship with husband } \\
\hline Strong & -0.47 & 1.43 & 1 & 0.23 & 0.62 & 0.29 & 1.35 & 28.9 \\
\hline Poor (r) & & & & & 1.00 & & & 54.9 \\
\hline \multicolumn{9}{|l|}{ Planned pregnancy } \\
\hline Unplanned & -0.63 & 2.76 & 1 & 0.10 & 0.53 & 0.25 & 1.12 & 28.6 \\
\hline Planned (r) & & & & & 1.00 & & & 49.3 \\
\hline Number of Children & & 6.00 & 4 & 0.20 & & & & \\
\hline No Child & -1.20 & 3.35 & 1 & 0.07 & 0.30 & 0.08 & 1.09 & 17.2 \\
\hline One & -0.21 & 0.16 & 1 & 0.69 & 0.81 & 0.29 & 2.28 & 34.9 \\
\hline Two & -0.48 & 0.80 & 1 & 0.37 & 0.62 & 0.21 & 1.78 & 30.8 \\
\hline Three & 0.44 & 0.50 & 1 & 0.48 & 1.56 & 0.46 & 5.28 & 55.0 \\
\hline Four or more & & & & & 1.00 & & & 52.9 \\
\hline \multicolumn{9}{|l|}{ Stressful life events* } \\
\hline None & -1.62 & 15.33 & 1 & 0.00 & 0.20 & 0.09 & 0.44 & 15.9 \\
\hline At least one (r) & & & & & 1.00 & & & 52.1 \\
\hline Constant & 0.99 & 5.13 & 1 & 0.02 & 2.70 & & & \\
\hline
\end{tabular}

*: Predictors with a $p<.05$, " $r$ ": Reference category, $d f$ degree of freedom, $p$-value, $B$ regression coefficient

Many Rwandans lost family members to the conflict and while Rwanda has a history of collective support, rebuilding trust and supports following the genocide has been a long process [47]. This renders new mothers more vulnerable to perinatal depression, which in turn affects the well-being of not only the women themselves but also the cognitive and emotional development of their children $[5,13]$. This study did not distinguish between losses that occurred during the genocide and those that occurred at other times; it would be helpful to know when and how these losses happened. Losses due to the genocide would be associated with an intensely traumatic event, which may not be the case for those due to illness or accidents, would carry a very different meaning and be understood differently, and would have happened 20 years in the past. As such, their impact may be very different from those losses sustained through other experiences, something which would benefit from further study. Another interesting area for further research would be to explore whether the impact of a poor relationship with a partner may be mitigated by other sources of support for women in these environments (e.g., peer support from neighbours or friends). Fisher and colleagues highlighted that nurturing and confiding intimate relationships exercise a protective influence on maternal mental health [8]. Building community in this way can also create better social environments and opportunities for the community as a whole, reinforcing how the well-being of mothers and their children is connected to that of their broader social environment, a point that is core to the Bronfenbrenner's social ecological model of development [48].

What was perhaps surprising was how few other variables of the larger social context were associated with symptoms of perinatal depression and anxiety. There was a difference between mothers of 4 or more children and those with no children, a pattern that has been observed elsewhere $[25,49]$. This may reflect the impact that having to manage a large family in a region with such limited resources can have on women's mental health. It should be noted, however, that the presence of other children in the household was not accounted for, including children of the woman's spouse, and thus the impact of the number of children may be understated here.

Higher socioeconomic and education levels have been found to be protective factors for mood and anxiety disorders in the perinatal period $[17,25]$ but while we found a link between the level of education and symptoms of perinatal depression using simple bivariate analyses, this effect disappeared in a multivariate analysis. For perinatal anxiety symptoms, there was no association with employment or education. However, there may have been a floor effect in this study, as most mothers (77\%) were unemployed, as were their spouses.

Likewise, in multivariate analyses, past stressful life events did not predict mothers' symptoms of perinatal 
depression despite their importance in other research $[17,18,24,25,38,50,51]$. However, exposure to extremely stressful past events was the only predictor of perinatal anxiety. It is important to note that the entire population underwent a traumatic event in recent history, the 1994 genocide against the Tutsi. It is possible that, in this context, the questions asked about the loss of family members and personal stressful life events did not adequately distinguish between the kinds of past trauma and loss women may have experienced in the context of predicting depression, or that there is a baseline of traumatic experience that all have already exceeded by virtue of living in a post-genocide society.

\section{Limitations to the study}

Our study's relatively small sample size may have lacked the power to identify more modest but important relationships between the variables under study, or to explore moderating relationships, and also limits its generalizability to Rwanda as a whole. There is also some concern regarding selection biases, given that it was a clinic-based study, and only in one district. As such it may underestimate the prevalence of symptoms of perinatal depression and anxiety because the mothers who did not attend their appointment time within the period of the study were not sampled and this may have precluded the most vulnerable mothers from the study. Women who may be suffering from symptoms of CPMD may lack the motivation or ability to visit a health facility, not only for themselves but also for the care of their infants. Moreover, women's social vulnerability differs from province to province in Rwanda, and thus these women may not be representative of the wider population. Thus, there is a need for community-based research in a wider range of provinces and districts to assess common perinatal mental disorders.

All variables were self-report and it is possible that women were not comfortable disclosing information about their own levels of distress as a result of concerns about social desirability and stigma or their spousal relationships. Nonetheless, it would have been informative to have more information about the level of conflict in women's relationships (e.g., violence or alcohol abuse). It would also have been informative to know more about the number of stressful events participants had been exposed to in their lifetime but this was not possible due to the way the data were collected. Knowing about whether stressful life events were experienced currently or in the past would also have been informative. The study is also limited by its cross-sectional design. Caution must be taken in assuming causal relationships between these variables. Longitudinal research is needed to explore whether causal relationships exist between these variables. Additionally, researchers only used screening tools, and so these findings do not reveal diagnostic rates of depression and anxiety diagnoses. Finally, research validating the EPDS or SAS to be reliable instruments in the Rwandan context is needed.

\section{Conclusions}

The high rates of symptoms of perinatal depression and anxiety indicate that it is imperative to include screening for CPMDs in order to improve detection and referral for interventions. Moreover, public education about CPMDs and training for all providers of services for pregnant and postpartum women is essential to increase awareness and early detection as well as to promote access to care.

This research raises important questions about associated factors of mental health in social contexts with limited social and material resources. The results here suggest that women in highly vulnerable environments may be particularly dependent on support available from their immediate social networks, which likely includes both material and social support, and particularly the presence of a good relationship with their husband/partner. Prevention strategies should focus on addressing the social conditions of women in the perinatal period. Health authorities and policy makers should consider the integration of maternal mental health care into maternal health. Thus, health care providers concerned should receive continuous professional development and in-service training enabling them recognizing risk factors, detecting and intervening early for women with CPMDs.

\section{Supplementary information}

Supplementary information accompanies this paper at https://doi.org/10. 1186/s12884-020-2747-z.

Additional file 1. Reviewer reports

\section{Abbreviations}

CPMD: Common perinatal mental disorders; EPDS: Edinburgh post natal depression scale; SAS: Self-rating anxiety scale

\section{Acknowledgements}

We acknowledge the Kigali Health Institute and Western University through the Maternal Newborn and Child Health Project for supporting this research. We also acknowledge the management of Nyamata Hospital and Health Centers for granting us permission to conduct our research in their area. We acknowledge Prof. David Cechetto, Ms. Bénoite Umubyeyi and Dr.

Arunarchallam for their guidance, encouragement and support.

\section{Authors' contributions}

PMU (University of Rwanda) conducted the research, drafted and revised the manuscript. OA (University of the Western Cape) provided supervision and guidance throughout the process of the research project and completion and revision of the manuscript. MH (York University) provided guidance throughout the process of the study and completion and revision of the manuscript. All authors read and approved the final manuscript.

\section{Funding}

This research was supported by a scholarship provided by a grant to Prof. David Cechetto, Western University, Canada, from the Department of Foreign Affairs, Trade and Development, Canada. This funding body paid PMU's school fees and facilitated data collection by providing transportation and 
paying the research assistant, though the research assistant was not involved in the design of the study, analysis, interpretation of data, or in writing the manuscript.

\section{Availability of data and materials}

The datasets used and analysed during the current study are available from the corresponding author on reasonable request.

\section{Ethics approval and consent to participate}

Ethical approval from the Senate Research Committee of the University of Western Cape/ South Africa (Certificate: 13/8/9) and Kigali Health Institute/ Rwanda Institutional Review Board (Certificate: KHI/IRB/26/2013) was obtained, as well as the written permission to collect data from the Director of the hospital. All participants provided written consent. Participants under the age of 18 (the age of majority in Rwanda), signed assent forms and their parents/guardians provided written consent.

\section{Consent for publication}

Not applicable.

\section{Competing interests}

The authors declare no competing interests.

\section{Author details}

${ }^{1}$ School of Nursing, College of Medicine and Health Sciences, University of Rwanda, 3286, Kigali, Rwanda. '2Department of Psychology, York University, 4700 Keele Street, Toronto, Ontario M3J 1P3, Canada.

Received: 28 February 2018 Accepted: 16 January 2020

Published online: 31 January 2020

\section{References}

1. Hanlon C, Medhin G, Alem A, et al. Detecting perinatal common mental disorders in Ethiopia: validation of the self-reporting questionnaire and Edinburgh postnatal depression scale. J Affect Disord. 2008;108:251-62.

2. Fisher J, Cabral de Mello M, Izutsu T, Tran T. The Ha Noi Expert Statement: recognition of maternal mental health in resource-constrained settings is essential for achieving the Millennium Development Goals. Int J Mental Health Syst. 2011;5(Suppl 2):2-6.

3. Stewart RC, Bunn J, Vokhiwa M, et al. Common mental disorder and associated factors amongst women with young infants in rural Malawi. Soc Psychiat Psychiatric Epid. 2009;45(Suppl 5):551-9.

4. McCaul A, Stokes J. Perinatal support to protect maternal mental health. Nurs Times. 2011;107(Suppl 48):16-8.

5. Rahman A, lqbal Z, Bunn J, et al. Impact of maternal depression on infant nutritional status and illness: a cohort study. Arch Gen Psychiat. 2004;61:946-52.

6. Rothera I, Oates M. Managing perinatal mental health: A survey of practitioners' views. Brit J Midwifery. 2011;19(Suppl: 5):304-16.

7. Dix T, Meunier LN. Depressive symptoms and parenting competence: an analysis of 13 regulatory practices. Develop Rev. 2009:29(Suppl 1):45-68.

8. Fisher J, Tran T, Kriitmaa K, Rosenthal D, Tuan T. Common perinatal mental disorders in northern Vietnam: community prevalence and health care use. B World Health Org. 2010;88(Suppl 10):737-45.

9. Harvey ST, Fisher LJ, Green VM. Evaluating the clinical efficacy of a primary care-focused, nurse-led, consultation liaison model for perinatal mental health. Intern J Mental Health Nurs. 2012;21:75-81.

10. Josefsson A, Sydsjö G. A follow-up study of postpartum depressed women: recurrent maternal depressive symptoms and child behavior after four years. Arch Womens Mental Health. 2007;10:141-5.

11. O'Hara MW, McCabe JE. Postpartum depression: current status and future directions. Ann Rev Clin Psychol. 2013;9:379-407. https://doi.org/10.1146/ annurev-clinpsy-050212-185612.

12. Field T. Postpartum depression effects on early interactions, parenting, and safety practices: a review. Infant Beh Dev. 2010;33(Suppl 1):1-6.

13. Patel V, Rahman A, Jacob KS, Hughes M. Effect of maternal mental health on infant growth in low income countries. New evidence from South Asia. BMJ. 2004;328(Suppl 3):820-3.

14. Austin MP. Classification of mental health disorders in the perinatal period: future directions for DSM-V and ICD-11. Arch Womens Ment Health. 2010;13:41-4.
15. Mwape L, McGuiness T, Dixey R, Johnson SE. Social-cultural factors surrounding mental distress during the perinatal period in Zambia: a qualitative investigation. Inter J Mental Health Syst. 2012;6(Suppl 12):1-10.

16. World Health Organization. Maternal mental health and child health and development in low and middle income countries: report of the WHOUNFPA meeting. Geneva: World Health Organization Press; 2008.

17. Fisher JT, Tran D, Nguyen T, Tran T. Common perinatal mental disorders and alcohol dependence in men in northern Vietnam. J Affect Disord. 2012; 140(Suppl 1):97-101.

18. Sawyer A, Ayers S, Smith H. Pre- and postnatal psychological wellbeing in Africa: a systematic review. J Affect Disord. 2010;123:17-29.

19. World Health Organization. Maternal mental health and child health and development in resource-constrained settings: Report of a UNFPANHO international expert meeting: the interface between reproductive health and mental health. Geneva: World Health Organization Press; 2009.

20. Fisher J, Cabral de Mello M, Patel V, Rahman A, Tran T et al.. Prevalence and determinants of common perinatal mental disorders in women in low- and lower-middle-income countries: a systematic review. Bul World Health Org 2012: 90; 139-149. doi: https://doi.org/10.2471/BLT.11.091850.

21. Gelaye B, Rondon BM, Araya R, Williams MA. Epidemiology of maternal depression, risk factors and child outcomes in low and middle income countries. Lancet Psych. 2016;3:973-82.

22. Adewuya $A$, Eegunranti $A B$, Lawal $A M$. Prevalence of postnatal depression in Western Nigerian women: a controlled study. Int J Psychiat Clin Pract. 2005; 9:60-4.

23. Hartley M, Tomlinson M, Greco E, Comulada WS, Stewart J. Depressed mood in pregnancy: prevalence and correlates in two Cape Town periurban settlements. Reprod Health J. 2011;8(Suppl 9):1-7.

24. Kakyo TA, Muliira JK, Mbalinda SN, et al. Factors associated with depressive symptoms among postpartum mothers in a rural district in Uganda. Midwifery. 2012;28(Suppl 3):374-9.

25. Giardinelli L, Innecnti A, Benni L, Stefanini MC, et al. Depression and anxiety in perinatal period: prevalence and risk factors in an Italian sample. Arch Womens Ment Health. 2012;15:21-30. https://doi.org/10. 1007/s00737-011-0249-8.

26. van Heyningen T, Honikman S, Myer L, Onah MN, Field S, Tomlinson M. Prevalence and predictors of anxiety disorders amongst low-income pregnant women in urban South Africa: a cross-sectional study. Arch Womens Ment Health. 2010;13:515-22.

27. Adewuya AO, Afolabi OT. The course of anxiety and depressive symptoms in Nigerian postpartum women. Arch Womens Mental Health. 2005;8:257-9.

28. Wittkowski A, Gardner PL, Bunton P, Edge D. Culturally determined risk factors for postnatal depression in Sub-Saharan Africa: A mixed method systematic review. J Affect Disord. 2014. https://doi.org/10.1016/j.jad.2013.12.028.

29. Sawyer A, Ayers S, Smith H, Sidibeh L, Nyan O, Dale J. Women's experiences of pregnancy and birth in the Gambia. A qualitative study. Br J Health Psychol. 2011:16:528-54.

30. National Institute of Statistics of Rwanda (NISR), Ministry of Finance and economic planning (MINECOFIN). Fourth population and housing census, Rwanda, 2012. 2015. http://www.statistics.gov.rw/publication/rphc4-atlas. Accessed 26 Nov 2017.

31. Munyandamutsa N, Mahoro NP, Gex-Fabry M, et al. Mental and physical health in Rwanda 14 years after the genocide. Soc Psychiat Psychiatric Epid. 2012:47:1753-61.

32. Cohen MH, Fabri M, Cai X, Shi Q, Hoover DR, Binagwaho A, et al. Prevalence and predictors of posttraumatic stress disorder and depression in HIV-infected and at-risk Rwandan women. J Women's Health. 2009;18(Suppl 11):1783-91.

33. Joharifard S, Rulisa S, Niyonkuru F, Weinhold A, Sayinzoga F, et al. Prevalence and predictors of giving birth in health facilities in Bugesera District, Rwanda. Lancet. 2012;12(Suppl 1049):1-10.

34. Ministry of Health, Rwanda. Annual Health Statistics Booklet 2011. Kigali: Ministry of Health; 2012. p. 1-50.

35. Tran TD, Tran T, Fisher J. Validation of three psychometric instruments for screening for perinatal common mental disorders in men in the north of Vietnam. J Affect Disord. 2012;136:104-9.

36. Tsai AC, Scott JA, Hung KJ, Zhu JQ, Matthews LT, Psaros C, et al. Reliability and Validity of Instruments for Assessing Perinatal Depression in African Settings: Systematic Review and Meta-Analysis. PLoS One. 2013;8(12):e82521. https://doi.org/10.1371/journal.pone.0082521.

37. Cox JL, Holden JM, Sagovesky R. Detection of postnatal depression: development of the 10-item Edinburgh postnatal depression scale. British J Psychiat. 1987;150:782-6. 
38. Nakku JEM, Nakasi G, Mirembe F. Postpartum major depression at six weeks in primary health care: prevalence and associated factors. Afr Health Sci. 2006;6:207-14.

39. Zung WWK. A rating instrument for anxiety disorder. Psychosomatics. 1971; 12(Suppl 6):371-9.

40. Polit DF, Beck CT. Nursing research: principals and methods. 7th ed. Philadeliphia: Lippincott; 2006.

41. Cochran WG. Sampling Techniques. 2nd ed. New York: Wiley; 1963.

42. Manikkam L, Burns JK. Antenatal depression and its risk factors: An urban prevalence study in KwaZulu-Natal. South Afric Med J. 2012;102(Suppl 12):940-4.

43. Rochat TJ, Tomlinson M, Barninghausen T, et al. The prevalence and clinical presentation of antenatal depression in rural South Africa. J Affect Disord. 2011;135:362-73.

44. Bennett HA, Einarson A, Taddio A, et al. Prevalence of depression during pregnancy: systematic review. Obstet Gynecol. 2004. https://doi.org/10. 1097/01.AOG.0000116689.75396.

45. Swalm D, Brooks J, Doherty D, et al. Using the Edinburgh postnatal depression scale to screen for perinatal anxiety. Arch Women's Mental Health. 2010;13:515-22.

46. Hynie M, Umubyeyi B, Gasanganwa MC, et al. Community resilience and community interventions for post-natal depression: Reflecting on maternal mental health in Rwanda. In: Khanlou N, Pilkington B, editors. Women's mental health: Resistance and resilience in community and society. Advances in Mental Health and Addiction (Series Editor: Masood Zangeneh). New York: Springer; 2015. p. 343-56.

47. King R, Hynie M, Mukashema I, Habineza JP, Kubwimana G, Musindarwego A. Integrating, complementary or just different? Western and Rwandan approaches to clinical counseling. Crit Radic Soc Work. 2016:4(Suppl 2):231-48.

48. Bronfenbrenner U. Contexts of child rearing: problems and prospects. Am Psychol. 1979;34(Suppl 10):84-850.

49. Joharifard S, Rulisa S, Niyonkuru F, et al. Prevalence and predictors of giving birth in health facilities in Bugesera District, Rwanda. BMC Public Health. 2012;12:1049. https://doi.org/10.1186/1471-2458-12-1049.

50. Seimyur L, Welles-Nystrom B, et al. A History of Mental Health Problems may predict maternal distress in women postpartum. Midwifery. 2013; 29(Suppl 2):122-31.

51. Howard LM, Oram S, Galley H, Trevillion K, Feder G. Domestic Violence and Perinatal Mental Disorders: A Systematic Review and Meta- Analysis. PLoS Med. 2013;10(5):e1001452. https://doi.org/10.1371/journal.pmed.1001452.

\section{Publisher's Note}

Springer Nature remains neutral with regard to jurisdictional claims in published maps and institutional affiliations.

Ready to submit your research? Choose BMC and benefit from:

- fast, convenient online submission

- thorough peer review by experienced researchers in your field

- rapid publication on acceptance

- support for research data, including large and complex data types

- gold Open Access which fosters wider collaboration and increased citations

- maximum visibility for your research: over $100 \mathrm{M}$ website views per year

At $\mathrm{BMC}$, research is always in progress.

Learn more biomedcentral.com/submissions 